\title{
Comparison of Formability and Microstructural Evolution of C106 Copper and 316L Stainless Steel
}

\author{
SCOTT TAYLOR, ${ }^{1,2}$ IAIN MASTERS, ${ }^{1}$ ZUSHU LI, ${ }^{1}$ \\ and HIREN R. KOTADIA ${ }^{1}$ \\ 1.-WMG, The University of Warwick, Coventry CV4 7AL, UK. 2.-e-mail: scott.taylor.1@ \\ warwick.ac.uk
}

\begin{abstract}
Strain-hardenable materials achieve their strength due to the build-up of defects and dislocation tangles within the microstructure brought about by strain induced through processing or forming. This strength can be significantly reduced and negatively impacted if the material is used in service at elevated temperatures, which causes the grain structure to recover and recrystallize to a more organized, lower strength state. Forming limit curves of C106 DHP copper and 316L stainless steel were established using an Interlaken hydraulic press with Nakajima punch tooling and GOM digital image correlation cameras. These formed samples were used as an analog to current formed parts, and the effect of extant elevated operating temperatures was then investigated by means of microhardness testing. High-resolution electron backscatter diffraction (EBSD) analysis using a JEOL JSM-7800F fieldemission gun scanning electron microscope was employed to understand the various mechanisms responsible for the physical and microstructural changes during forming and at elevated temperatures.
\end{abstract}

\section{INTRODUCTION}

A return to previous production methods can lead to unforeseen issues, as changes in material standards can mean that current materials have different properties from those used previously. Stricter rules regarding health and safety also mean that consumables such as lubricants must change to meet new standards. Also, loss of knowledge and expertise due to staff retirement or loss can also mean that reinitiation of a run of parts after a prolonged break can prove difficult. Approximately 40 years ago, parts were formed from C106 copper without any recorded issues, but on return to this process, part failures were observed during downstream processing.

A working hypothesis for the cause of these failures is microstructural instabilities within the C106 whilst at elevated temperatures. This paper presents a study on the feasibility of replacing a current forming material with a new material (316L stainless steel) to alleviate these issues. The suitability of the proposed replacement material was assessed based on its improved formability, increased strength, and enhanced microstructural stability at elevated temperatures. $316 \mathrm{~L}$ was selected as a potential substitute owing to its compatibility with downstream processing, and its weldability and ability to be highly polished, both of which are industrial requirements.

Copper alloys such as C106 are employed in various industrial processes that require good formability and high strength, and is widely formable using a variety of conventional and advanced processes. ${ }^{1}$ Its high formability in the annealed state where the material has an organized structure, and its ability to readily strain-harden during forming due to point defects and dislocation tangles within the microstructure, avoid the need for expensive post forming heat treatments, in contrast to materials such as aluminum. ${ }^{2}$

The suitability of copper for use in higher-temperature applications is limited due to its propensity to recover and recrystallize to an ordered structure at elevated temperatures, which leads to a significant reduction in strength and large levels of grain growth over a prolonged period of time. ${ }^{3}$ The reduction in material strength can be detrimental if the application requires a specific level of strength greater than that of annealed copper. In such 
applications, alternative materials such as steels, which are less susceptible to softening and annealing at these temperatures, must be employed. ${ }^{4}$

Austenitic stainless steels such as 316L are highstrength materials and, like copper, strain-harden throughout forming; however, they can operate in higher-temperature environments than copper without losing strength or mechanical performance. ${ }^{5}$ C106 copper undergoes stress relief at around $200^{\circ} \mathrm{C}$ and is annealed at upwards of $350^{\circ} \mathrm{C},{ }^{6}$ so operating temperatures of $500^{\circ} \mathrm{C}$ would fully recover and recrystallize the material, and prolonged exposure would lead to unwanted grain growth. $^{7}$ 316L steel undergoes stress relief at temperatures of above $450^{\circ} \mathrm{C}$ for around $1 \mathrm{~h}$, and the annealing temperature is $1040^{\circ} \mathrm{C}$ upwards. ${ }^{8}$ This ability to withstand higher temperatures before recovery and recrystallization suggests that $316 \mathrm{~L}$ is a suitable substitute for $\mathrm{C} 106$ for use at operating temperatures of around $500^{\circ} \mathrm{C}$.

In the work presented herein, forming limit curve (FLC) testing was used to establish the formability of these materials. The FLC is a graphical representation of the major and minor surface strains experienced within a material under specific forming conditions. Above this curve, localized necking, instability, and subsequent failure are observed, while beneath this curve, "safe" forming conditions are observed. Within this safe area, however, there are various regions where issues with wrinkling or partially formed parts may occur. ${ }^{9}$

Testing was conducted using a Nakajima hemispherical tool directly in contact with the test piece. ${ }^{10}$ Nakajima testing is well established for the determination of forming limit curves for various materials including copper and steel. ${ }^{11,12}$ Samples with different geometries were prepared to give varied strain paths. DIC was used to analyze the samples during deformation and establish the peak strains observed within the test piece immediately prior to failure. ${ }^{13}$

Samples from Nakajima testing offer a very close analog to parts that are formed in the extant industrial process. Samples from the FLC trials were then exposed to elevated temperatures to simulate industrial downstream processing, to investigate the reduction in strength in various regions. The evolution of the material microstructures pre and post forming and post heat treatment was then investigated using wide-field electron backscatter diffraction (EBSD) analysis.

\section{EXPERIMENTAL PROCEDURES}

Two materials were investigated, viz. 316L stainless steel and C106 Cu-DHP copper; their compositions are presented in Table I. The materials were nominally supplied in annealed condition as $0.5 \mathrm{~mm}$ sheet, and no further thermomechanical processing was applied to either material prior to testing.

Forming limit curves were established using an ITC Interlaken $1000 \mathrm{kN}$ hydraulic press operating a Nakajima punch and smooth clamp ring set. Tests were run at constant punch speed of $1 \mathrm{~mm} / \mathrm{s}$. Samples were computer numerical control (CNC) machined into five geometries to give varied strain paths $(40 \mathrm{~mm}, 60 \mathrm{~mm}, 120 \mathrm{~mm}, 140 \mathrm{~mm}$, and $178 \mathrm{~mm}$ discs) from sheet material as shown in Fig. 1, and a white-on-black speckled paint pattern was applied. Testing was conducted according to ISO 16808:2014. ${ }^{14}$ GOM Aramis $5 \mathrm{mp}$ cameras and software were used to establish the surface strain across the samples by means of DIC.

For microstructural analysis, samples were cut from a representative area of the sheet material, and ground and polished using standard metallographic techniques. Microstructural characterization was conducted using a JEOL JSM-7800F FEGSEM with Symmetry electron backscatter detectors and Oxford Aztec software. Settings were optimized for each test, and an aperture size of $240 \mathrm{~mm}$ with accelerating voltage of $20 \mathrm{keV}$ was used across all tests. In the case of electron backscattering, a stage tilt of $70^{\circ}$ running for $12 \mathrm{~min}$ with average step size of $0.7 \mu \mathrm{m}$ was used across all tests.

Microhardness testing was conducted using a Wilson VH1202 hardness tester operating in $0.05 \mathrm{Hv}$ mode according to ISO $6507-1: 2018 ;^{15}$ the samples were prepared as for EBSD analysis to achieve a defect-free highly polished surface. Samples were taken from unformed sheet and also from seven regions from across formed and sectioned FLC samples, both before and after exposure to a heat treatment to mimic industrial processes. The heat treatment profile is illustrated in Fig. 2a, and the regions for microhardness testing are identified in Fig. 2b. An average of nine indents were applied in each region, and any anomalous results were discarded.

\section{RESULTS AND DISCUSSION}

FLCs for the 316L and C106 materials are shown in Fig. 3a, and failed samples of C106 are shown in Fig. $3 \mathrm{~b}$, revealing failure at the center of the

Table I. Composition of materials tested during this study (wt.\%)

\begin{tabular}{|c|c|c|c|c|c|c|c|c|c|}
\hline Material & $\mathbf{F e}$ & $\mathbf{C u}$ & $\mathbf{C}$ & $\mathbf{P}$ & Mn & $\mathrm{Cr}$ & $\mathbf{N i}$ & Mo & $\mathbf{N}$ \\
\hline $316 \mathrm{~L}$ & Balance & - & $\leq 0.030$ & - & $\leq 2.00$ & $16.0-18.0$ & $10.0-14.0$ & $2.00-3.00$ & $\leq 0.10$ \\
\hline C106 & - & 99.85 & - & $0.0-0.15$ & - & - & - & - & - \\
\hline
\end{tabular}


samples in accordance with the test standard. These results show that the $316 \mathrm{~L}$ steel exhibited greater levels of formability across all geometries and strain paths. This suggests that, for applications where C106 material is currently employed, 316L will be capable of forming the same geometries.

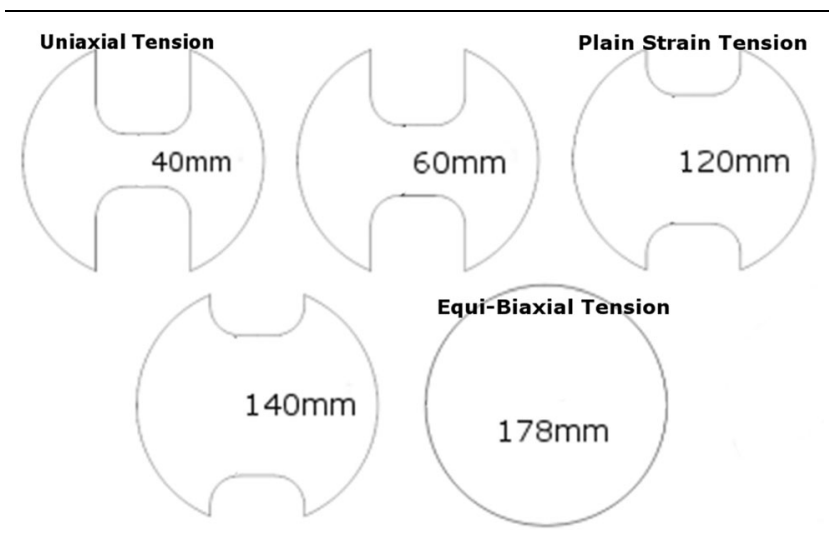

Fig. 1. Geometries of machined FLC samples used during testing.
Additionally, the material will be further from its forming limit and will therefore have improved physical characteristics. Peak forming loads of $48 \mathrm{kN}$ and $85 \mathrm{kN}$ were observed for $\mathrm{C} 106$ and $316 \mathrm{~L}$, respectively, due to the higher strength of the steel. The increased formability of $316 \mathrm{~L}$ means that it could form more complex geometries, allowing for design modifications to parts without having to change material.

The hardness values for $\mathrm{C} 106$ and $316 \mathrm{~L}$ in asreceived condition were $74 \mathrm{Hv}$ and $162 \mathrm{Hv}$, respectively. As expected, both materials were observed to strain harden during FLC testing (Fig. 4). The lower-strength $\mathrm{C} 106$ exhibited an increase to $88 \mathrm{Hv}$ in the clamped region, while $316 \mathrm{~L}$ was unaffected. Region 2, where the materials were bent at $90^{\circ}$ into the tool, exhibited a sharp increase in hardness, while a reduced value was found in region 3 due to the lower levels of deformation in this region. Peak hardness values of $108 \mathrm{Hv}$ in C106 and $315 \mathrm{Hv}$ in $316 \mathrm{~L}$ were observed in region 7 near to failure at the peak of the dome, corresponding to major strains of $45 \%$ and $63 \%$, respectively.
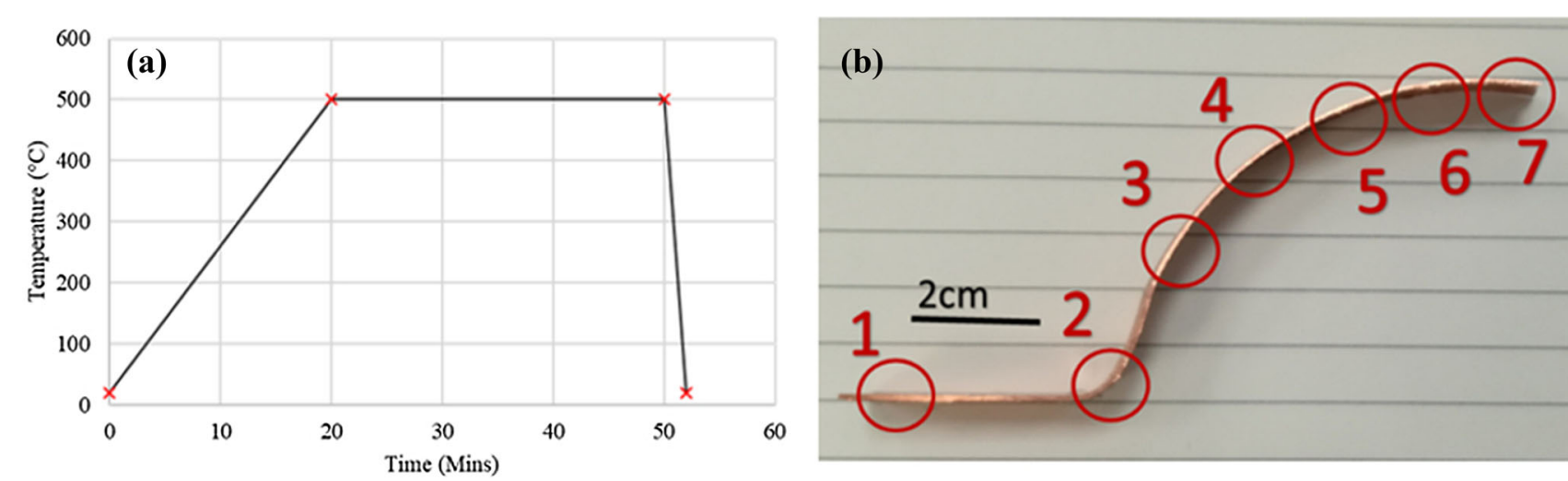

Fig. 2. (a) Heat treatment regime. (b) Regions across FLC samples for microhardness testing.

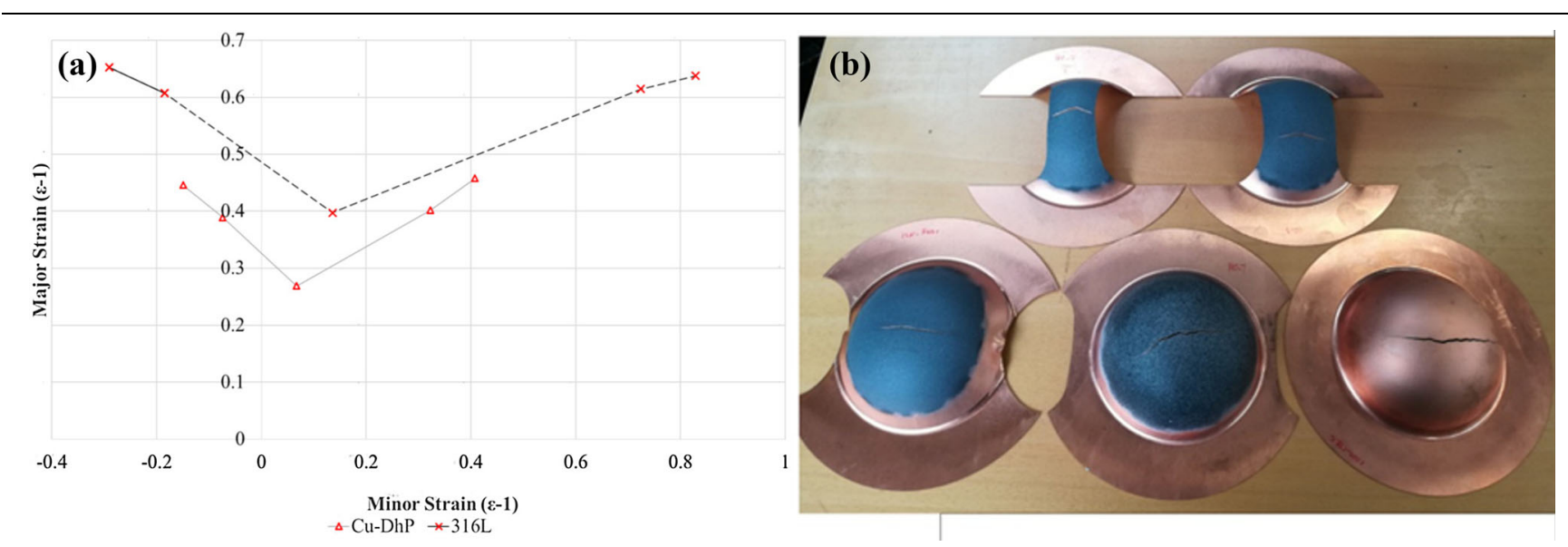

Fig. 3. (a) Forming limit curves of $\mathrm{C} 106$ copper and $316 \mathrm{~L}$ stainless steel. (b) Failed samples of $\mathrm{C} 106$ copper showing speckled pattern. 
Following exposure to $500^{\circ} \mathrm{C}$ for $30 \mathrm{~min}, \mathrm{C} 106$ softened significantly, with a $24 \%$ peak reduction in hardness in region 7 and an average $14.5 \%$ reduction across all regions. The hardness of $316 \mathrm{~L}$ remained virtually unchanged after heating, with an average $0.35 \%$ reduction over all regions and an increase of $1.2 \%$ in peak hardness, significantly less than the standard deviation within the results. C106 underwent significant softening due to initiation of recovery then recrystallization of the material at the elevated temperature, leaving it in a lower-strength, organized state. The temperature was below that of recovery or recrystallization for $316 \mathrm{~L}$, leaving the material unchanged post heating, as confirmed by the results of EBSD analysis.

EBSD imaging of both C106 and 316L in the asreceived annealed condition showed a microstructure with equiaxed grains, as would be expected. The inverse pole figure (IPF) shading, which assigns

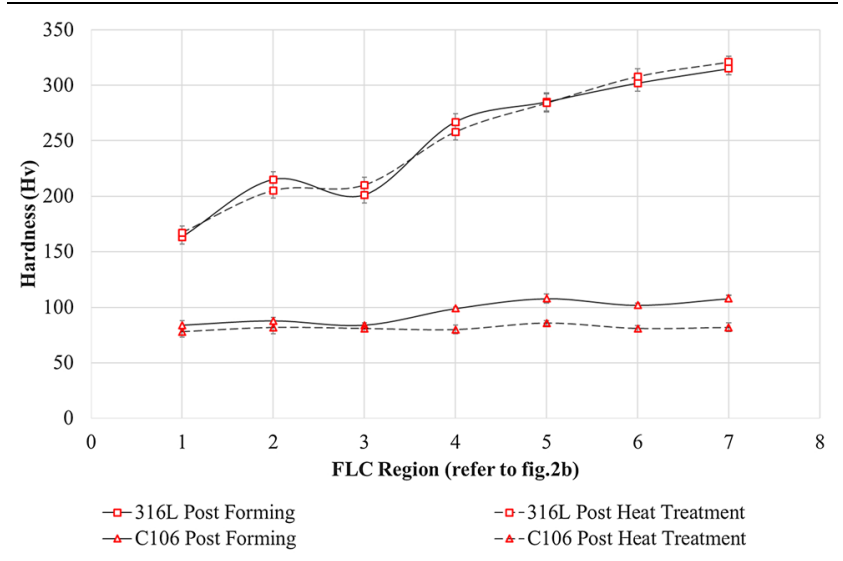

Fig. 4. Comparison of microhardness across formed FLC samples for both $\mathrm{C} 106$ and $316 \mathrm{~L}$ post forming and post heat treatment. a color to a crystal according to its orientation, shows some residual evidence of the rolling direction with a higher fraction of $<111>$-oriented grains (Fig. 5). The average grain size was $12.7 \mu \mathrm{m}$ and $13.1 \mu \mathrm{m}$ for the $\mathrm{C} 106$ and $316 \mathrm{~L}$ material, respectively. Both materials showed annealing twins, which play an important role in the recrystallization process by enabling a mechanism for increased grain growth when the process has halted.

EBSD images of the clamped region of a $40-\mathrm{mm}$ C106 FLC sample are illustrated following deformation in Fig. $6 \mathrm{a}$ and post heat treatment in Fig. 6b. Following heat treatment, there was obvious grain growth within the material, with the average grain size increasing from $15.5 \mu \mathrm{m}$ in Fig. 6a to $22.6 \mu \mathrm{m}$ in Fig. 6b. Imaging of the failed region is shown in Fig. 6c, with grains heavily elongated in the direction of deformation. Missing data in Fig. 6c are due to zero indexing as a result of the deformation to the sample.

Post heat treatment (Fig. 6d), no evidence of the deformation remained; indeed, the material appeared to be fully recrystallized with a uniaxed grain structure similar to that of the as-received material. Textural analysis of the failed regions showed a reduction of the multiple of uniform density (MUD) from 7.9 to 2.1 following heat treatment. This much weaker texture indicates that the material was fully recrystallized following heat treatment. This microstructural instability is understood to be one of the limiting factors within current industrial applications.

Corresponding regions of a 316L FLC sample are illustrated in Fig. 7. Contrary to the C106 sample, there is no evidence of grain growth or microstructural evolution following heat treatment within the clamped region (Fig. 7a and b). The average grain size for these samples was $13.5 \mu \mathrm{m}$ and $13.7 \mu \mathrm{m}$,
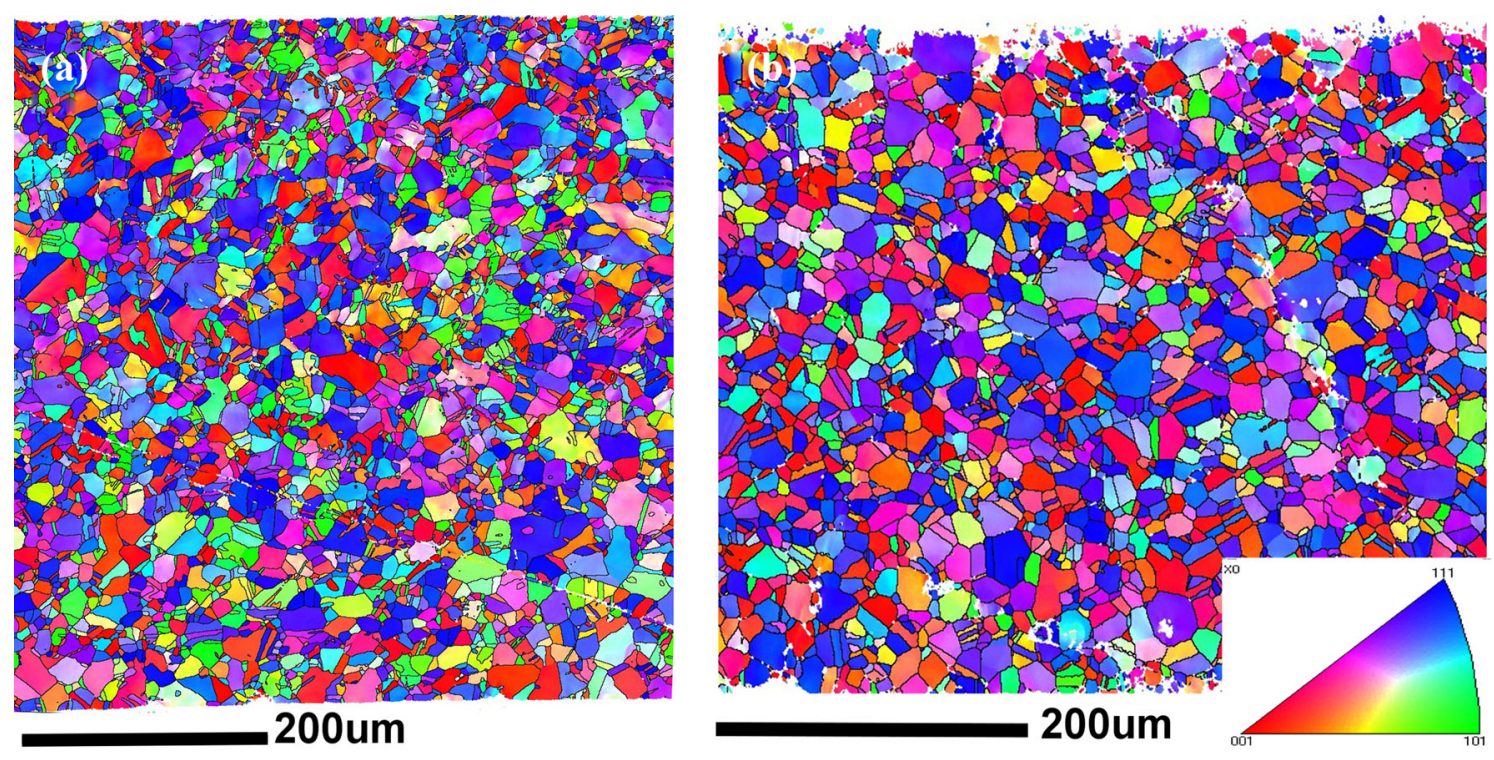

Fig. 5. EBSD imaging of as-received (a) C106 and (b) as 316L; IPF shading legend shown in image. 


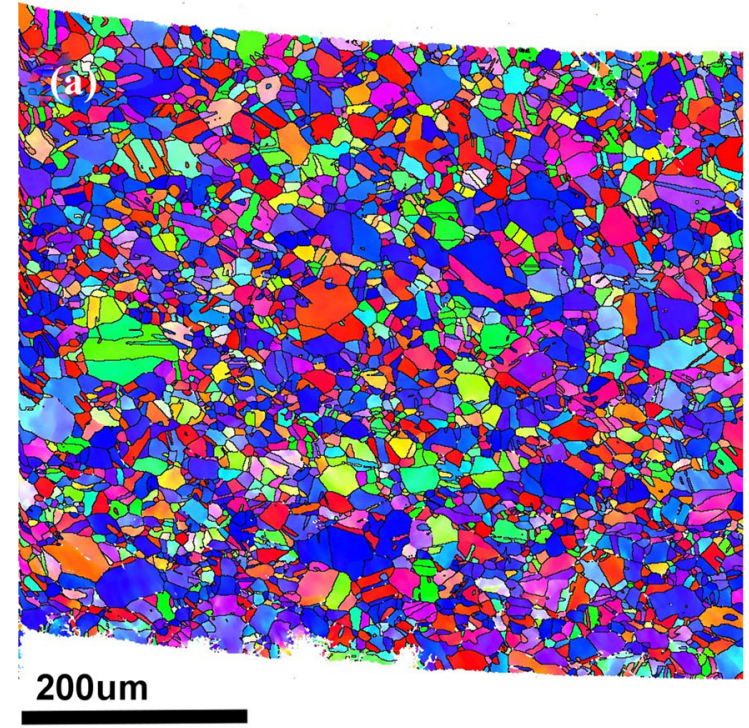

(c)

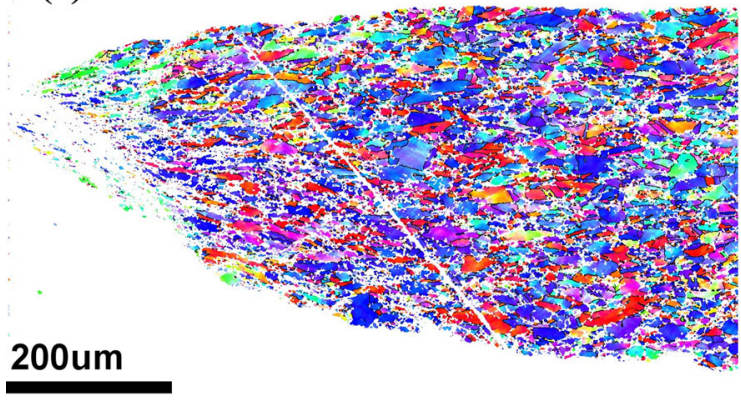

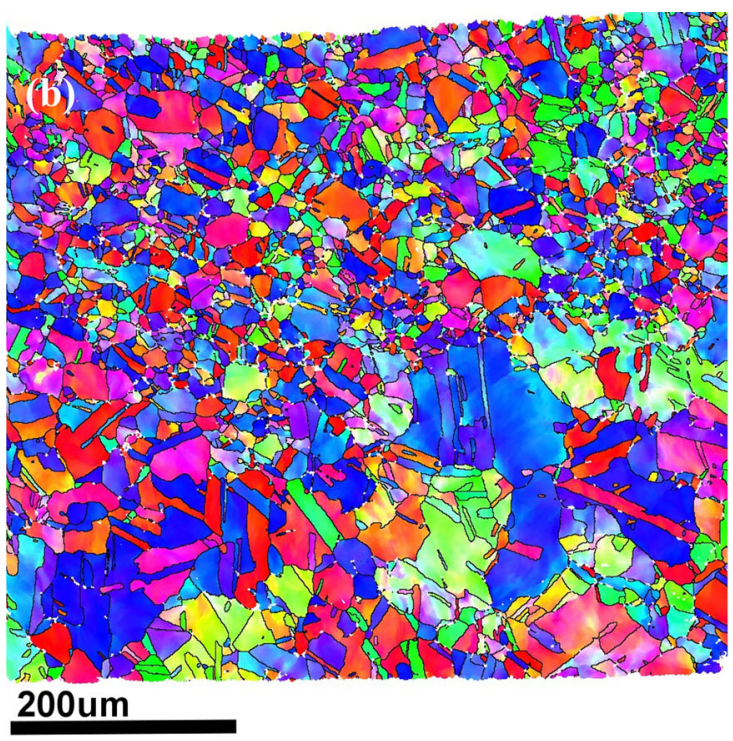

(d)

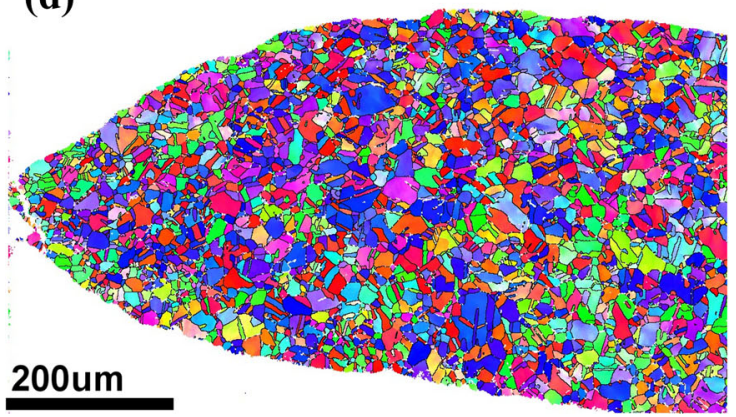

Fig. 6. Microstructural evolution of C106 material: (a) in region 3 post forming, (b) in region 3 post heat treatment, (c) in region 7 post forming, and (d) in region 7 post heat treatment; individual scale bars shown for each sample.

respectively. Textural values for this region were nearly identical, with low MUDs of 2.9 and 3.0 for Fig. $7 a$ and $b$, due to the lack of deformation in this region.

Imaging of the deformed region pre and post heat treatment is shown in Fig. 7c and d. A highly deformed microstructure with elongated grains is observed in both cases, with average size of $14.1 \mu \mathrm{m}$ and $14.3 \mu \mathrm{m}$. Textural analysis gave high MUD values of 13.0 and 13.2 for Fig. 7c and d, respectively. These high values are due to the high levels of deformation within this region, similar to that at the failure point. The unchanged textural value is indicative of a stable microstructure with no recovery or recrystallization occurring. This stable microstructure is desirable for compatibility with downstream industrial processing.

\section{CONCLUSION}

316L stainless steel offers a viable higherstrength alternative to C106 copper for use in elevated-temperature applications. C106 suffered a
$24 \%$ reduction in hardness when exposed to elevated temperatures for a 30-min cycle, whilst $316 \mathrm{~L}$ was almost unaffected, losing only $0.35 \%$ in hardness.

EBSD analysis revealed that, following a 30-min heat treatment at $500^{\circ} \mathrm{C}, \mathrm{C} 106$ was fully recovered and recrystallized with a grain structure resembling that of the as-supplied annealed sheet material. The microstructure of $316 \mathrm{~L}$ was unaffected by this heat treatment, showing no evidence of any recovery or recrystallization taking place; indeed, samples were left in an identical state to post forming samples.

The increased formability and strength of 316L combined with its stable microstructure at extant operating temperatures mean that it is a viable alternative to $\mathrm{C} 106$ for use in current industrial forming applications. The stable microstructure and ability to retain strength at elevated temperature also ensure its compatibility with downstream industrial processing. 

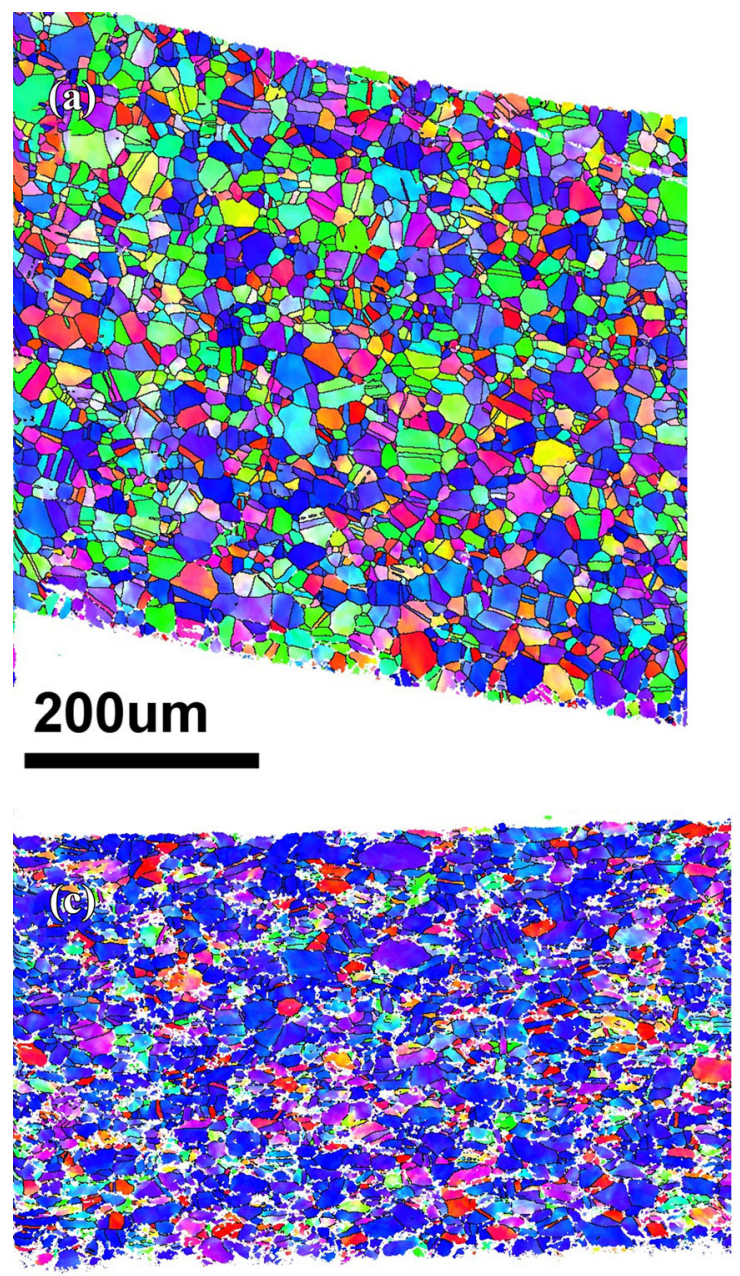

200um
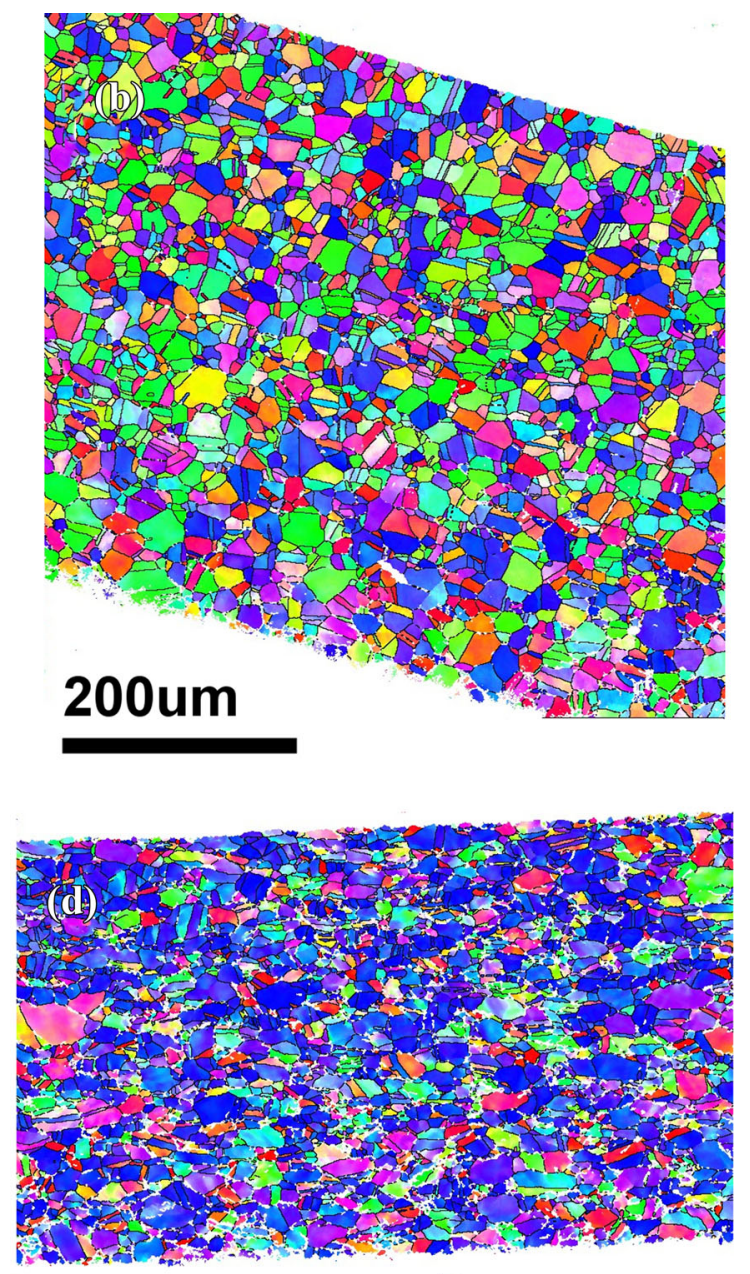

200um

Fig. 7. Microstructural evolution of 316 L material: (a) in region 3 post forming, (b) in region 3 post heat treatment, (c) in region 7 post forming, and (d) in region 7 post heat treatment; individual scale bars shown for each sample.

\section{ACKNOWLEDGEMENTS}

The key funding of this project as well as the supply of the materials is from Atomic Weapons Establishment (AWE). In addition, the characterization facility is supported from the Higher Education Funding Council for England (HEFCE) fund, and the WMG Centre High Value Manufacturing Catapult is gratefully acknowledged.

\section{OPEN ACCESS}

This article is distributed under the terms of the Creative Commons Attribution 4.0 International License (http://creativecommons.org/licenses/by/4. $0 /$ ), which permits unrestricted use, distribution, and reproduction in any medium, provided you give appropriate credit to the original author(s) and the source, provide a link to the Creative Commons license, and indicate if changes were made.

\section{REFERENCES}

1. F. Mandigo and J. Crane, Forming of copper and copper alloys.ASM Handbook Vol 14 Forming and Forging, ed. S.L. Semiatin (Ohio: ASM International, 1998), .

2. T. Inaba, Automobile aluminium sheet.Automotive Engineering; Lightweight Functional and Novel Materials, ed. B. Cantor, P. Grant, and C. Johnston (Boca Raton: CRC Press, 2008), pp. 19-27.

3. J.R. Davis, et al., Copper and Copper Alloys, ASM Speciality Handbook, 2nd ed. (ASM International: Ohio, 2008).

4. Copper Development Association, Copper and Copper Alloys, Compositions, Applications and Properties (Copper Development Association, 2004), https://copperalliance.eu/u ploads/2018/03/pub-120-copper-and-copper-alloys.pdf. Accessed 8 Sept 2018.

5. A. Kosmač, Stainless Steels at High Temperatures First Edition (Materials and Applications Series), Vol. 18 (Brussels: Euro Inox, 2012).

6. H. Lipowsky, Copper in the Automotive Industry (Weinheim: Wiley, 2007).

7. D. Raabe, Recovery and recrystallization: phenomena, physics, models, simulation.Physical Metallurgy, 5th ed., ed. D.E. Laughlin and K. Hono (Amsterdam: Elsevier, 2014), pp. 2291-2395. 
8. M.K. Herliansyah, P. Dewo, M.H. Soesatyo, and W. Siswomihardjo, Conference Paper, ICICI-BME, Bandung (2015).

9. W.C. Emmens, Springer Briefs in Applied Sciences and Technology (Springer, Berlin, 2011), pp. 15-24.

10. M.B. Silva, K. Isik, E.K. Tekkaya, and P.A.F. Martins, Acta Metall. Sin. 28, 1415 (2015).

11. M. Turkoz, H.S. Halkaci, O. Yigit, M. Dilmec, and F. Ozturk, Proc. Inst. Mech. Eng. Part B J. Eng. Manuf. 228, 450 (2014).

12. R. Amaral, A.D. Santos, and S. Miranda, IOP Conf. Ser. J. Phys. 843, 1 (2017).

13. GOM International, Material Properties: Determination of Process Limitations in Sheet Metal Forming-Forming Limit Diagram (GOM International, 2009), https://www.g
om.com/fileadmin/user_upload/industries/flc_fld_EN.pdf. Accessed 8 Sept 2018.

14. BS EN ISO 16808:2014, Metallic Materials-Sheet and Strip-Determination of Biaxial Stress-Strain Curve by Means of Bulge Test with Optical Measuring Systems (ISO 16808:2014) (British Standards International, 2014).

15. BS EN ISO 6507-1:2018, Metallic Materials. Vickers Hardness Test. Test Method (British Standards International, 2018).

Publisher's Note Springer Nature remains neutral with regard to jurisdictional claims in published maps and institutional affiliations. 